\title{
Identification and application of anti- inflammatory compounds screening system based on RAW264.7 cells stably expressing NF-kB-dependent SEAP reporter gene
}

Yue Li $i^{1,2}$, Xiaomeng Wang ${ }^{3}$, Juan Ren ${ }^{4}, X_{i} \operatorname{Lan}^{1,2}$, Jing Li ${ }^{1,2}$, Jing Yi ${ }^{1,2}, \mathrm{Li} \mathrm{Liu}^{1,2}$, Yan Han ${ }^{1,2}$, Sanqi Zhang ${ }^{3}$, Dongmin $\mathrm{Li}^{1,2^{*}+}$ and Shemin $\mathrm{Lu}^{1,2^{*+}}$

\begin{abstract}
Background: NF-KB is one of the key transcription factors in the inflammatory response, transactivates a series of pro-inflammatory genes and is therefore regarded as an important target for anti-inflammatory drug screening.

Method: We recombined the reporter gene vector with inserting the "neo" transcript into the vector pNF-KB-SEAP, made the reporter gene vector stable in a eukaryotic cell line. The recombinant reporter gene vector we named pNF-KB-SEAP-Neo was transfected into RAW264.7. We selected the transfected RAW264.7 cell line with G418 for 15 days and then get RAW264.7 cells stably expressing NF-KB-dependent SEAP named as RAW264.7-pNF-KB-SEAP cells. We treated the RAW264.7-pNF-KB-SEAP cells with NF-KB agonists as LPS, Polyl:C and TNF-a, NF-KB inhibitor as PDTC and BAY117085, in different concentrations and time points and tested the expression of the SEAP, constructed the drug screening system on the base of the RAW264.7-pNF-kB-SEAP cell line. 130 chemicals were screened with the drug screening system we constructed and one of these chemicals numbered w10 was found could inhibit the NF-KB significantly. At last, we verified the inhibition of w10 to expression of genes promoted with NF-kB in HepG2 and Hela, and to migration of Hela.

Result: In this study, we established a drug screening system based on RAW264.7 cells that stably expressed the NF-KB-dependent, SEAP reporter gene. To develop a standard method for drug screening using this reporter-gene cell line, the test approach of SEAP was optimized and basic conditions for drug screening were chosen. This included the initial cell number inoculated in a 96-well plate, the optimum agonist, inhibitor of NF-kB pathway and their concentrations during screening. Subsequently, 130 newly synthesized compounds were screened using the stable reporter-gene cell line. The anti-inflammatory effects of the candidate compounds obtained were further verified in 2 cancer cell lines. The results indicated that compound W10 (methyl 4-(4-(prop-2-yn-1-ylcarbamoyl) phenylcarbamoyl) benzoate) significantly inhibited SEAP production under the screening conditions. Further results confirmed that the precursor compound significantly inhibited the transcription of NF-KB target genes.
\end{abstract}

Conclusion: In conclusion, RAW264.7 cells, stably expressing the NF-kB-dependent SEAP-reporter gene, may provide a new, feasible, and efficient cellular drug-screening system.

Keywords: Reporter gene, Inflammation, Drug screening, Signal pathway

\footnotetext{
* Correspondence: lidongm@mail.xjtu.edu.cn; lushemin@mail.xjtu.edu.cn

${ }^{\dagger}$ Equal contributors

'Department of Biochemistry and Molecular Biology, School of Basic Medical

Sciences, Xi'an Jiaotong University Health Science Centre, Xi'an, Shaanxi

710061, People's Republic of China

Full list of author information is available at the end of the article
} 


\section{Background}

Inflammation is a defence response to infection, injury, and/or stress. When acute inflammatory response is triggered, it lasts for a short period and is regulated by negative feedback signals. Dysregulation of this feedback mechanism results in chronic inflammation, which is believed to be a key pathophysiological mechanism in various health disorders. In metabolic syndrome, for example, inflammation seems to be instrumental in the pathogenesis of insulin resistance and hepatic steatosis $[1,2]$, In various cancers, the inflammatory milieu provides a favourable condition for malignant cells to proliferate and migrate [3].

The macrophage, which is ubiquitously-distributed, plays an important role in inflammation. Its functions include phagocytosis, antigen presentation and secretion of different types of cytokines and chemokines to regulate inflammation. In insulin resistance associated with metabolic syndrome, macrophages secrete proinflammatory cytokines such as tumour necrosis factor (TNF)- $\alpha$ and interleukin (IL)-1 $\beta$ [4] while in primary and metastatic tumours, they provide a proinflammatory microenvironment for cancer cell growth [5]. Based on their role in inflammation, macrophage activation has been recognized as a target for anti-inflammation therapy. One of the signal transduction pathways involved during macrophage activation is the nuclear factor- $\mathrm{k} B(\mathrm{NF}-\mathrm{k} B)$ pathway.

$\mathrm{NF}-\mathrm{kB}$ is a nuclear transcription factor and contains 5 subunits: c-Rel, RelA (p65), RelB, NF-kB1 (p50 and p105), and NF- $k B 2$ (p52 and p100) [6]. Inactive NF-kB forms a trimer consisting of RelA, p50, and inhibitor protein $\mathrm{I} \kappa \mathrm{B}$ in the cytoplasm. During canonical activation IкB is phosphorylated, separates from the heterodimer RelA/p50 and is degraded via ubiquitination [7]. At the same time, the phosphorylated RelA/p50 dimer translocates into the nucleus, and binds with cis-acting transcription elements in its target genes [8] to form a transcription complex. NF- $\mathrm{kB}$ is known to activate the transcription of more than 400 genes [9]. During acute inflammation such as in bacterial infection, activation of NF- $\mathrm{kB}$ up-regulates transcription of various cytokines and chemokines that promote the inflammatory response and antigen presentation; while during chronic inflammation, NF- $\mathrm{KB}$ triggers the transcription of more complicated genes that are involved in growth, transformation, and survival of cells [10]. Another difference between acute and chronic inflammation is that NF-kB is activated for short and long periods, respectively [11]. In both, metabolic syndrome and cancer, NF- $\mathrm{B}$ is activated continuously to promote transcription of several proinflammatory cytokines [12]. NF- $\mathrm{BB}$ also up-regulates proliferation and migration of tumour cells [6] and plays a major role in the inflammatory microenvironment of the tumour [3]. Besides being a direct trigger and regulator of the inflammatory response, NF- $\mathrm{KB}$ is itself regulated through crosstalk with other intracellular signalling pathways [13]. Therefore, macrophages and NF-kB are both considered as important cellular and molecular screening targets for anti-inflammation and anti-cancer drugs [14].

In drug screening, the strategy strikingly depends on the target choice and the assay method [15]. Recently, molecules of the signalling pathway have become new target choices for drug screening. Compared with targeting cellular receptors, signal pathway molecules represent the activation or inhibition of a compound within the signal pathway more directly, thus requiring identification of the mechanism of action of the screened compound. Regarding assay methods, secreted alkaline phosphatase (SEAP) is extensively used in the detection of positive candidates [16]. The gene encoding SEAP has been used as a reporter gene in screening and its activity is represented by SEAP-expression yield. SEAP catalyses p-nitrophenyl phosphate (PNPP) into 4-NPP, transforming to yellow and soluble quinones with maximum absorption wavelength at $405 \mathrm{~nm}$ [17]. Thus, SEAP activity can be measured in terms of concentration of quinones produced in presence of SEAP. SEAP has several advantages as a reporter gene for drug screening: feasibility of application within the culture supernatant, high stability at $65{ }^{\circ} \mathrm{C}$, and prolonged half-life [18].

In this study, we constructed a drug screening system targeting the NF- $\mathrm{kB}$ pathway in macrophages. We produced a recombinant $\mathrm{pNF}-\mathrm{kB}-\mathrm{SEAP}$ vector, transfected mouse macrophages, and obtained a cell line stably expressing the reporter gene. We optimized conditions for the SEAP test and basic conditions of recombined cell culture and treatment with well-known activators and inhibitors of the NK- $\mathrm{kB}$ pathway. A total of 130 newlysynthesized compounds were screened using this drug screening system and 8 compounds displayed striking inhibitory activity for SEAP. Compound W10 was selected to evaluate the screening results in HeLa and HepG 2 cells, and the results showed that W10 significantly inhibited the expression of NF- $\mathrm{KB}$ targeting genes.

\section{Methods}

\section{Recombination of vector PNF-KB-SEAP}

To recombine the vector $\mathrm{pNF}-\kappa \mathrm{B}-\mathrm{SEAP}$ to be stable in eukaryocyte, we analysed the vector sequence (http:// www.addgene.org) and found that there are 2 restriction sites (SalI and AfeI) downstream of the SEAP transcript. The vector $\mathrm{pEGFP-N1}$ (Clontech) includes the sequence of neomycin resistance gene "neo". Therefore, the open reading frame for "neo" was first amplified (forward primer: 5'-GCGTCGACGTCCTGAGGCGGAAAGAA-3'; reverse primer: 5'-CCAGCGCTGGGGTATGTAGGC 
GGTGCTAC-3') at $71{ }^{\circ} \mathrm{C}$ annealing temperature, for 35 cycles. Subsequently, the 2024-bp target fragment and the vector $\mathrm{pNF}-\mathrm{kB}-\mathrm{SEAP}$ were digested with the restriction enzymes SalI and AfeI (Fermentas) and then joined by T4 DNA ligase (TAKARA) (Fig. 1a). Lastly, the recombinant plasmid, pNF- $\mathrm{B}-\mathrm{SEAP}-\mathrm{Neo}$, was sequenced (Beijing Genomics Institute).

\section{Establishment of RAW264.7 cells stably expressing NF-KB-} dependent SEAP reporter gene

RAW264.7 cells obtained from the Cell Bank of the Chinese Academy of Sciences (Shanghai, China),were cultured in RPMI 1640 medium (Hyclone) with 10\% heat-inactivated foetal bovine serum (FBS; Hyclone) at $37{ }^{\circ} \mathrm{C}$ under $5 \% \mathrm{CO}_{2}$ and passaged every 2 days. At the third passage, the cells were inoculated into 6-well plates with $1 \times 10^{6}$ per well and cultured overnight until the cells reached $80 \%-90 \%$ confluence. The plasmid pNFкB-SEAP-Neo was extracted with an Endo free Plasmid Mini preparation Kit (Omega) and its concentration was determined using a Nanodrop (Thermo Fisher) spectrophotometer. The extracted pNF-кB-SEAP-Neo was transfected into RAW264.7 cells using Fugene ${ }^{\curvearrowleft}$ HD Transfection Reagent (Promega). To form the transfection complex, the medium was removed from the wells and $2 \mathrm{~mL}$ fresh RPMI 1640 medium was added. Following this, $2 \mu \mathrm{g}$ plasmid and $8 \mu \mathrm{L}$ Transfection Reagent diluted in $100 \mu \mathrm{L}$ RPMI 1640 medium without serum were mixed for $1 \mathrm{~s}$ and added to the wells in a drop-wise manner, swirled to ensure that the transfection complex covered the entire plate surface, and incubated for $15 \mathrm{~min}$ at room temperature.

After transfection with pNF-kB-SEAP-Neo plasmid for $24 \mathrm{~h}, \mathrm{RAW} 264.7$ cells were selected with $200 \mu \mathrm{g} /$ mL G418 (Ameresco). Fresh medium containing $200 \mu \mathrm{g} /$ $\mathrm{mL}$ G418 was replenished every other day, for 15 days. The positive clones of RAW264.7-pNF-kB-SEAP cells were cultured and proliferated in RPMI 1640 medium with $10 \% \mathrm{FBS}$ and $200 \mu \mathrm{g} / \mathrm{mL} \mathrm{G} 418$, at $37{ }^{\circ} \mathrm{C}$ under $5 \%$ $\mathrm{CO}_{2}$, and designated as RAW264.7-pNF-кB-SEAP cells.

\section{Alkaline phosphatase activity assay}

Pure CIAP (Takara) was serially diluted in ultrapurewater to obtain a series: $0.8 \times 10^{-2}, 1.6 \times 10^{-2}, 2.4 \times 10^{-2}$, $3.2 \times 10^{-2}$, and $4.0 \times 10^{-2} \mathrm{U} / \mathrm{mL}$. The substrate reaction buffer was prepared by dissolving PNPP (Sigma-Aldrich) in $1 \mathrm{mg} / \mathrm{mL}$ diethanolamine (DEA) buffer $(0.1 \mathrm{moL} / \mathrm{L}$ DEA, $1 \mathrm{moL} / \mathrm{L} \mathrm{MgCl} 2$, pH 9.8). Subsequently, $50 \mu \mathrm{L}$ substrate was mixed with $50 \mu \mathrm{L}$ standard alkaline phosphatase solution and left to react at $37{ }^{\circ} \mathrm{C}$ for $30 \mathrm{~min}$ in the dark. The microplate was then placed in an ice-bath to end the reaction. The absorbance of the product was read at $405 \mathrm{~nm}\left(\mathrm{OD}_{405}\right)$ and ultrapure-water is used to adjust zero, using a full-wavelength microplate reader

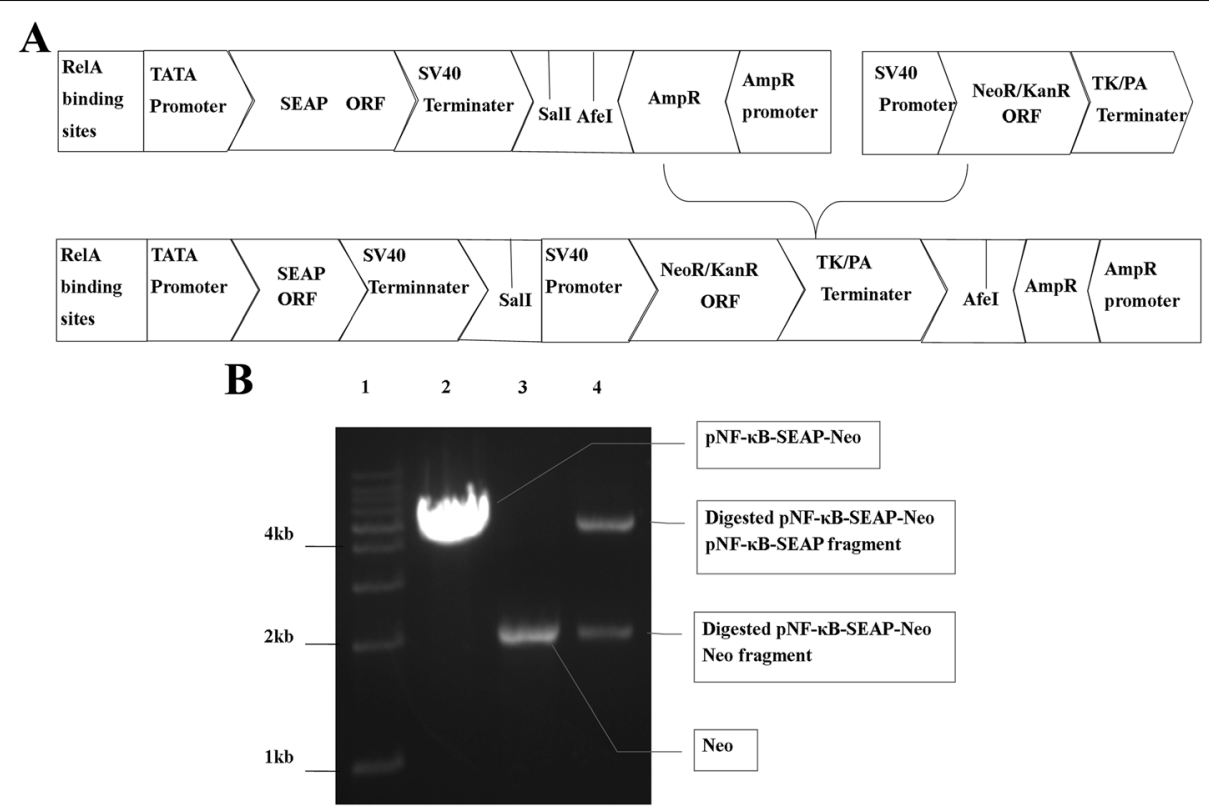

Fig. 1 Recombined reporter gene vector pNF-KB-SEAP-Neo. a Schematic diagram of the recombined reporter gene vector pNF-KB-SEAP-Neo. The ORF of eukaryotic/ prokaryotic resistance gene NeoR/KanR was amplified from pEGFP-N1 vector and inserted into pNF-kB-SEAP vector between 2 restriction sites of Sall and Afel to construct the recombined vector pNF-KB-SEAP-Neo. b Identification of recombined reporter gene vector pNF-KB-SEAP-Neo. Double-restriction-enzyme digestion analysis of Sall and Afel was performed with 1\% agarose gel electrophoresis. Lane 1 is the 1-kb ladder marker. Lane 2 is the restriction enzyme-digested products of the reporter gene vector pNF-KB-SEAP. Lane 3 is the restriction enzyme-digested products of amplified "Neo" transcript. Lane 4 is the restriction enzyme-digested products of the recombined reporter gene pNF-KB-SEAP-Neo 
(Thermo). Taking $\mathrm{OD}_{405}$ as the abscissa and CIAP activity as the ordinate, a standard curve for SEAP activity was obtained.

When analysing SEAP activity in the culture supernatant, we collected the culture supernatant $(150 \mu \mathrm{L}$ per well) and heated it at $65{ }^{\circ} \mathrm{C}$ for $5 \mathrm{~min}$ to inactivate other alkaline phosphatases in the cells and the serum, and mixed $50 \mu \mathrm{L}$ culture supernatant with $50 \mu \mathrm{L}$ substrate reaction buffer at $37{ }^{\circ} \mathrm{C}$ and left it to react for $30 \mathrm{~min}$ in the dark. The microplates were then placed in an icebath to end the reaction. Absorbance of the product was read at $405 \mathrm{~nm}\left(\mathrm{OD}_{405}\right)$ and fresh medium without SEAP was used to adjust zero, using a full-wavelength microplate reader (Thermo). The absorbance was considered directly proportional to the activity of SEAP in the cell supernatant.

\section{Optimizing the drug screening system with RAW264.7- pNF-KB-SEAP}

To determine the optimum number of cells in the initial inoculum for drug screening, the cells were inoculated in a 96-well plate at concentrations of 10,000, 20,000, 40,000, 80,000 and 160,000 cells/well, cultured for $8 \mathrm{~h}$, and incubated in $150 \mu \mathrm{L} /$ well of high-glucose DMEM without phenol red (Hyclone) and with or without lipopolysaccharide (LPS) $(100 \mathrm{ng} / \mathrm{mL})$ for $24 \mathrm{~h}$. SEAP activity in the culture supernatant was measured by microplate spectrometry.

To determine a suitable NF- $\mathrm{B}$ agonist for RAW264.7pNF- $\kappa$ B-SEAP cells, the cells were treated with NF- $\mathrm{B}$ pathway agonists such as LPS, PolyI:C, and TNF- $\alpha$ at different concentrations. SEAP activity in the culture supernatant was measured at different time points using microplate spectrometry.

The optimal quantity of RAW264.7-pNF-кB-SEAP cell inoculum was added to a 96-well plate and cultured in high-glucose DMEM without phenol red at $37{ }^{\circ} \mathrm{C}$ and $5 \% \mathrm{CO}_{2}$ for $8 \mathrm{~h}$. The cells were then treated for $24 \mathrm{~h}$ with $0.1,1,10$, or $100 \mathrm{ng} / \mathrm{mL}$ LPS (Sigma-Aldrich); 1, 10, or $100 \mu \mathrm{M}$ PolyI:C (Amacia); 1, 10, or $100 \mathrm{ng} / \mathrm{mL}$ TNF- $\alpha$ (Peprotech); or in the absence of an agonist as the control. Following this, the concentrations of SEAP in the samples and control were determined and relative expression of SEAP (fold) was calculated using the equation:

The relative expression of SEAP (fold) $=\frac{\text { SEAP concentration in the sample }}{\text { SEAP concentration inthe control }}$

Similarly, after inoculation in a 96-well plate and incubated in high-glucose DMEM without phenol red at $37^{\circ} \mathrm{C}$ and $5 \% \mathrm{CO}_{2}$ for $8 \mathrm{~h}$, the cells were treated with $100 \mathrm{ng} / \mathrm{mL}$ LPS, 10nM Polyl:C, or $10 \mathrm{ng} / \mathrm{mL}$ TNF- $\alpha$ for 6,12 , or $24 \mathrm{~h}$, or without any agonist as the control. SEAP concentration in the samples and control were determined and the relative activity of SEAP (fold) was calculated using the above equation.

To determine a NF- $\mathrm{kB}$ inhibitor positive control for the drug screening system, RAW264.7-pNF-kB-SEAP cells were treated with NF- $\mathrm{BB}$ inhibitors pyrrolidinedithiocarbamate (PDTC) [19] or (2E)-3-[[4-(1,1-Dimethylethyl) phenyl] sulfonyl]-2-propenenitrile (BAY117085) [20].

After the cells were inoculated in a 96-well plate and cultured with high-glucose DMEM without phenol red at $37{ }^{\circ} \mathrm{C}$ and $5 \% \mathrm{CO}_{2}$ for $2 \mathrm{~h}$, RAW264.7-pNF-кB-SEAP cells with the optimal quantity of inoculum were treated with PDTC (Beyotime) and BAY117085 (Beyotime) at the concentrations of $0.1,1,10$, and $100 \mu \mathrm{M}$ for $6 \mathrm{~h}$ or with $1 \%$ DMSO $(\mathrm{v} / \mathrm{v})$ for $6 \mathrm{~h}$ as the control. Then, they were cultured in high-glucose DMEM without phenol red containing $100 \mathrm{ng} / \mathrm{mL}$ LPS for $24 \mathrm{~h}$. SEAP concentrations in the samples and control were determined and the relative expression of SEAP (fold) was calculated using the above equation.

\section{The screening compounds}

Using our established system, we screened several series of compounds, including compounds labelled W (N-(prop-2-ynyl)-4-(substituted phenylcarbonylamino) benzamides) [21], compounds labelled K (2-arylisoquinoline-1, 3(2H, 4H)-diones [22], compounds labelled $\mathrm{Z}$ (N-aryl salicylamides) [23], compounds labelled X (diaryl urea) [24], and compounds labelled S (5-(2aminobenzo[d] hiazole-6-yl)-2-methoxy-3-(phenylsulfonylamino) benzamides) [25].

Our final screened compound W10 was synthesised as follows. To the solution of methyl 4-(chlorocarbonyl) benzoate $(0.60 \mathrm{~g}, 3 \mathrm{mmol})$ in anhydrous THF $(10 \mathrm{ml})$, a solution of 4-amino-N-(prop-2-yn-1-yl) benzamide $(0.20 \mathrm{~g}, 1 \mathrm{mmol})$ and diisopropylethylamine $(1.00 \mathrm{ml}$, $0.006 \mathrm{~mol})$ in anhydrous THF $(10 \mathrm{ml})$ was added dropwise at $0{ }^{\circ} \mathrm{C}$. The reaction mixture was then stirred for $3.5 \mathrm{~h}$ at room temperature. After evaporating the solvent, the residue was dissolved in ethyl acetate $(20 \mathrm{ml})$. The mixture was washed with water, followed by washing with $1 \mathrm{M}$ sodium hydroxide, $1 \mathrm{M}$ diluted hydrogen chloride, and brine; dried over sodium sulphate; and filtered. The filtrate was evaporated under reduced pressure to afford a white solid of $0.21 \mathrm{~g}$. A yield of $67.0 \%$ was obtained. W10 is methyl 4-((4-(prop-2-ynylcarbamoyl) phenylcarbamoyl) benzoate with its melting point between $240{ }^{\circ} \mathrm{C}$ and $242{ }^{\circ} \mathrm{C}$. 1H-NMR (400 MHz, DMSO-d6): $\delta 10.66(\mathrm{~s}, 1 \mathrm{H}), 8.87(\mathrm{~s}, 1 \mathrm{H}), 8.10(\mathrm{~s}, 4 \mathrm{H})$, 7.89 (s, 4H), 4.06 (s, 2H), 3.90 (s, 3H), 3.13 (s, 1H). HRMS $\mathrm{m} / \mathrm{z}$ Calculated for C19H17N2O4 $[\mathrm{M}+\mathrm{H}]+$ 337.1188, found 337.1178 [21]. 
Screening of 130 compounds to find NF-KB inhibitors and verification of the inhibitory effect of the screened compound (W10)

After RAW264.7-pNF-кB-SEAP cells at the optimal inoculum concentration were added to 96-well plates and cultured in high-glucose DMEM without phenol red at $37{ }^{\circ} \mathrm{C}$ and $5 \% \mathrm{CO}_{2}$ for $2 \mathrm{~h}$, these cells were treated with each of the 130 compounds at the concentration of $10 \mu \mathrm{M}$ for $6 \mathrm{~h}$ or with $1 \%$ DMSO (v/v) for $6 \mathrm{~h}$ as the control. The cells were then cultured in high-glucose DMEM without phenol red, containing $100 \mathrm{ng} / \mathrm{mL}$ LPS for $24 \mathrm{~h}$. Lastly, SEAP concentration in the samples and control was calculated and the inhibition ratio of compounds to NF- $\mathrm{kB}$ was determined using the following equation:

$$
\begin{aligned}
& \text { Inhibitory ratio }(\%)=(1-\text { relative activity of SEAP }) \\
& \times 100
\end{aligned}
$$

We tested the inhibitory effect of W10 on the transcription of genes promoted by NF- $\mathrm{kB}$ in tumour cell lines where NF- $\mathrm{kB}$ is known to be continuously activated. HepG 2 and HeLa cell lines obtained from the Cell Bank of the Chinese Academy of Sciences (Shanghai, China) were chosen for this purpose. After inoculation in 6-well plates at a concentration of $3 \times 10^{5}$ cells/well and incubation in high-glucose DMEM at $37{ }^{\circ} \mathrm{C}$ with $5 \% \mathrm{CO}_{2}$ for $12 \mathrm{~h}$, HepG 2 and HeLa cells were each, treated with $10^{-5}$ $\mathrm{M}$ W10, $10^{-5} \mathrm{M}$ PDTC or $1 \%$ DMSO (v/v) for $24 \mathrm{~h}$ or $48 \mathrm{~h}$ respectively. We extracted total RNA from these samples and tested the transcription of cyclooxygenase (COX)-2, monocyte chemoattractant protein (MCP) 1, and intercellular adhesion molecule (ICAM) 1, which are known to be promoted by NF-kB.

\section{Scratch assay}

We inoculated Hela cells at a concentration of $3 \times 10^{5}$ cells/well in 6-well plate and incubated in high-glucose DMEM at $37{ }^{\circ} \mathrm{C}$ with $5 \% \mathrm{CO}_{2}$ for $12 \mathrm{~h}$, marking off in the cells with $10 \mu \mathrm{L}$ tip as straight as possible. The Hela cells with mark-off line were treated with 1\% DMSO (v/ v) and $10^{-5} \mathrm{M}$ W10 in high-glucose DMEM without FBS for $24 \mathrm{~h}$ or $48 \mathrm{~h}$ respectively. The scratches in cells were observed and photographed with inverted microscope (Nikon Eclipse $\mathrm{Ri}$ ) at $24 \mathrm{~h}$ and $48 \mathrm{~h}$. The 3 fixture positions were selected then photographed and measured width of the scratches at the positions at $24 \mathrm{~h}$ and $48 \mathrm{~h}$, statistical the variation of scratches width.

\section{Real-time quantitative polymerase chain reaction}

Total RNA from the samples was extracted with TriPure Isolation Reagent (Roche) as follows: After removing the medium, $1 \mathrm{~mL}$ reagent was added into each well, incubated for $5 \mathrm{~min}$, and then transferred to a fresh $1.5-\mathrm{mL}$
Eppendorf tube, where chloroform $(0.2 \mathrm{ml}$ per $1 \mathrm{ml}$ of TriPure) was added. Then, the tubes were vortexed for mixing, followed by centrifugation at $12,000 \mathrm{~g}$ and $4{ }^{\circ} \mathrm{C}$ for $15 \mathrm{~min}$ till the liquid separated into 3 phases. The aqueous phase was transferred carefully to a new tube, mixed with an equal volume of isopropanol, vibrated gently, and incubated at $-20{ }^{\circ} \mathrm{C}$ overnight to precipitate RNA. The mixture was centrifuged at $12,000 \mathrm{~g}$ and $4{ }^{\circ} \mathrm{C}$ for $15 \mathrm{~min}$; then, isopropanol was discarded and $75 \%$ ethanol was added. The mixture was subjected to gentle vibration and centrifuged again at $12,000 \mathrm{~g}$ and $4{ }^{\circ} \mathrm{C}$ for $15 \mathrm{~min}$. The ethanol was then removed and placed at room temperature until the RNA was dry and then retrieved with $10 \mu \mathrm{L}$ diethylpyrocarbonate in water. The quantity of the RNA was estimated using a Nanodrop (Thermo Fisher) spectrophotometer.

Using RNA from the samples as template, cDNA was prepared and amplified (First Strand cDNA Synthesis Kit, Thermo). The amplification system included $5 \mu \mathrm{g}$ total RNA and $1 \mu \mathrm{L}$ oligo (dT) primer, and the total volume made up to $12 \mu \mathrm{L}$ with water. This system was incubated at $65{ }^{\circ} \mathrm{C}$ for $5 \mathrm{~min}$, cooled quickly on ice and the following reagents were added to a final volume of $20 \mu \mathrm{L}: 4 \mu \mathrm{L} 5 \times$ Reaction Buffer, $1 \mu \mathrm{L}$ RiboLock RNase Inhibitor $(20 \mathrm{U} / \mu \mathrm{L}), 2 \mu \mathrm{L}$ dNTP Mix $(10 \mathrm{mM})$, and $1 \mu \mathrm{L}$ RevertAid M-MuLV RT $(200 \mathrm{U} / \mu \mathrm{L})$. The amplification mixture was mixed gently, centrifuged instantaneously, and incubated at $42{ }^{\circ} \mathrm{C}$ for $60 \mathrm{~min}$. The whole amplification reaction was terminated at $70{ }^{\circ} \mathrm{C}$ for $5 \mathrm{~min}$.

In HeLa and HepG 2 cell lines, the transcription of genes encoding MCP1, COX-2, and ICAM1 was detected using real-time quantitative polymerase chain reaction (RTqPCR), with iQ5 (Bio-Rad, Hercules, USA) and FastStart Universal SYBR Green Master (ROX) (Roche) for 40 cycles. The relative gene expression normalized by $\beta$-actin was calculated by the 2- $\Delta \Delta \mathrm{CT}$ method. Details of the primers used are shown in Additional file 1: Table S1.

\section{Statistics}

All experiments were repeated 3 times, with 3 replicates per analysis. Significance of difference between samples and control was determined using the 1 way-ANOVA. All raw values were transformed with EXCEL 2010 and statistical analysis was performed using Prism 6.0 software.

\section{Results}

Establishment of RAW264.7-pNF-KB-SEAP cells stably expressing NF-KB-dependent SEAP reporter gene

The reporter gene vector (Clontech) is a transienttransfection plasmid and does not contain the eukaryotic resistant gene for stable transfection. Therefore, it is not suitable for establishment of the drug screening system (Fig. 1a). There are 2 restriction sites (SalI and AfeI) 

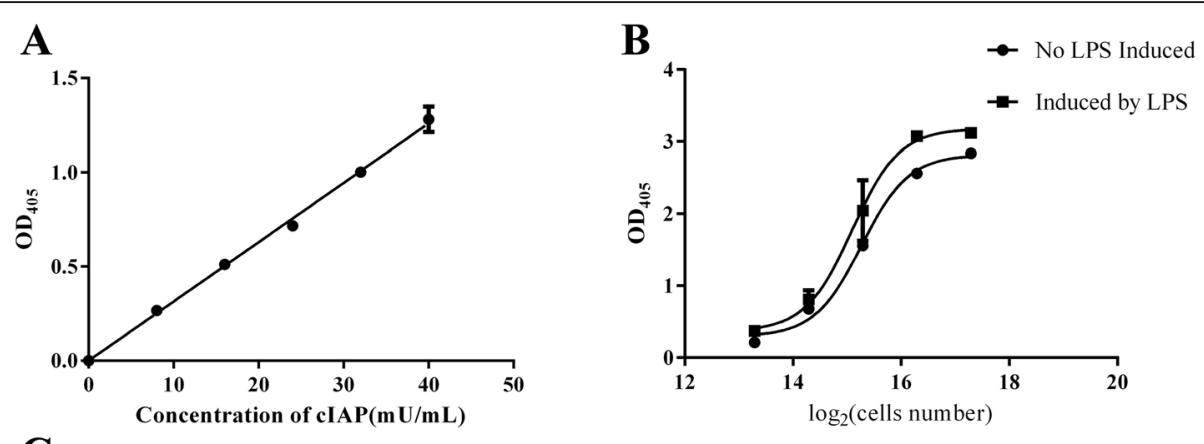

C
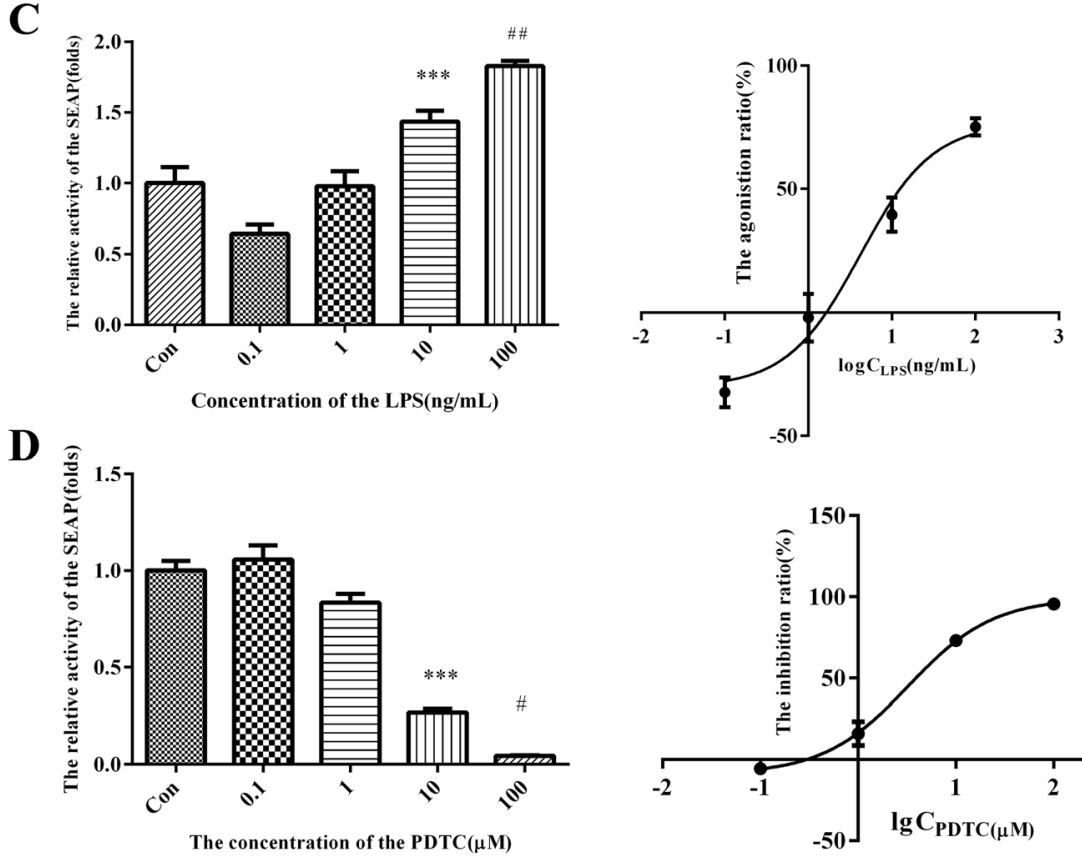

$\mathbf{E}$
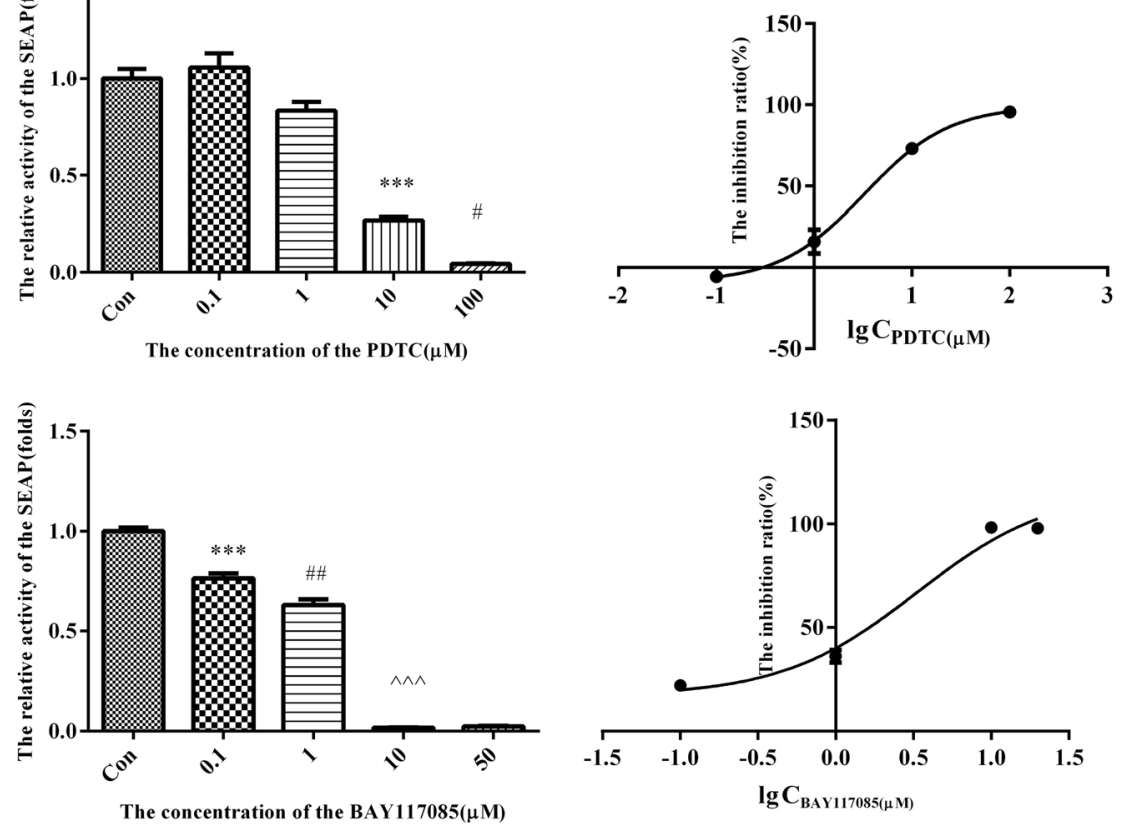

Fig. 2 (See legend on next page.) 


\begin{abstract}
(See figure on previous page.)
Fig. 2 Identification of standard screening method based on RAW264.7 Cell line stably expressing NF-KB-dependent SEAP reporter Gene. a Standard curve of alkaline phosphatase, $y=0.0315 x, R^{2}=0.9947$. $\mathbf{b}$ Relationship between $\mathrm{OD}_{405}$ and cell number/well of Raw264.7 cells stably expressing NF-kB dependent SEAP reporter gene (RAW264.7-pNF-KB-SEAP cells)treated with or without LPS. $R^{2}=0.9395$ (the cells were treated with LPS), and $R^{2}=0.9910$ (the cells were treated without LPS). $\mathbf{c}$ The effect of RAW264.7-pNF-KB-SEAP cells were treated with different concentrations of LPS for $24 \mathrm{~h}$ menifested as column chart of relative activity of SEAP and dose-response stimulation curve with common logarithm of LPS concentration as the ordinate and the stimulation ratio (\%) as the abscissa, $R^{2}=0.9643$. $\mathbf{d}$ The RAW264.7-pNF-kB-SEAP cells were treated with PDTC at concentrations of $0.1,1,10$, and $100 \mu \mathrm{M}$ or $1 \%$ DMSO (v/v) (as control) for $6 \mathrm{~h}$ and then treated with LPS in $100 \mathrm{ng} / \mathrm{mL}$ for $24 \mathrm{~h}$. The effect of PDTC on RAW264.7-pNF-kB-SEAP cells was manifested as column chart of relative activity of SEAP and the dose-response inhibition curve between the $\log _{10}$ concentrations of PDTC and the inhibition ratio calculated from SEAP relative activity, $R^{2}=0.9802$, their relation according to the common logarithmic equation. e The RAW264.7-pNF-KB-SEAP cells were treated with BAY117085 at concentrations of 0.1, 1, 10, and 50 $\mu \mathrm{M}$ or 1\%o DMSO (v/v) (as control) for $6 \mathrm{~h}$ and then treated with LPS in $100 \mathrm{ng} / \mathrm{mL}$ for $24 \mathrm{~h}$. The effect of BAY117085 on RAW264.7-pNF-kB-SEAP cells was manifested as column chart of relative activity of SEAP and the dose-response inhibition curve between the $\log _{10}$ concentrations of BAY 117085 and the inhibition ratio calculated from SEAP relative activity, $R^{2}=0.9735$, their relation according to the common logarithmic equation. The "**" indicates that the column had significant difference compared with the control, the others marked as "\#" and " $\wedge$ " indicate that the column showed significant difference compared with the column on the left
\end{abstract}

downstream of the SEAP transcript in the vector pNF$\kappa B-S E A P$. We amplified the fragment of neomycin resistance geneNeoR/KanR ORF and TK-PA-terminator in the vector pEGFP-N1,inserted the fragment into downstream of SEAP transcript of pNF-kB-SEAP (Fig. 1a). The amplified fragment was 2,042 bp long (Fig. 1b). Both pNF-кB-SEAP and the amplified fragment were digested with SalI and AfeI (Fig. 1b) and then linked to construct the recombinant SEAP reporter gene vector (pNF-кB-SEAP-Neo) (Fig. 1a and b). The positive recombinant including pNF-KB-SEAP-Neo was selected on Luria Bertani agar with ampicillin and then proliferated in order to extract endotoxin-free plasmid for eukaryotic transfection. DNA sequencing showed that there was no mutation in the amplified fragment of the recombinant vector pNF-кB-SEAP-Neo.

The extracted pNF-kB-SEAP-Neo was transfected into RAW264.7 cells. By selection with fresh medium containing $200 \mu \mathrm{g} / \mathrm{mL}$ G418for 15 days,the RAW264.7 cells stably expressing the SEAP reporter gene (RAW264.7pNF-кB-SEAP cells) were established.

\section{Alkaline phosphatase activity assay}

SEAP reporter gene expression is indicated by its activity; therefore, the concentration of SEAP was determined as its activity per unit volume. Since there is a high level of similarity between SEAP and calf intestine alkaline phosphatase (CIAP), the standard curve of SEAP activity was prepared using CIAP. In the standard curve, the abscissa denotes different concentrations of the standard substance, CIAP; the ordinate denotes $\mathrm{OD}_{405}$, indicating the activity of alkaline phosphatase under different concentrations of CIAP (Fig. 2a and Additional file 2). Since CIAP is highly similar to SEAP except for the signal peptide, the ordinate denotes $\mathrm{OD}_{405}$, it also reflects the activity of alkaline phosphatase under different concentrations of SEAP. The equation of standard curve is $\mathrm{y}=0.000315 \mathrm{x}$ and $\mathrm{R}^{2}=0.9947$.
Therefore, SEAP activity in the culture supernatant can be calculated using this standard curve or equation using their $\mathrm{OD}_{405}$ values.

\section{Construction of a drug screening system based on the recombined cell line, RAW264.7-pNF-KB-SEAP}

In order to select the optimal initial inoculum of cells for anti-inflammatory drug screen, the activity of SEAP in culture supernatant of the RAW264.7-pNF-kB-SEAP cells with different inocula per cell was determined in the presence or absence of LPS $(100 \mathrm{ng} / \mathrm{mL})$ for $24 \mathrm{~h}$. The results showed that the relationship between the $\log _{2}$ of initial inoculum and $\mathrm{OD}_{405}$ was consistent with the agonist dose-response curve, when the initial inoculum ranged from 20,000 to 160,000cells/well (Fig. 2b and Additional file 2). Furthermore, when the initial inoculum was 40,000 cells/well, the $\mathrm{OD}_{405}$ in the presence of LPS was significantly higher than that in the absence of LPS. Therefore, we selected 40,000 cells of RAW264.7-pNF-kB-SEAP cells/well in a 96-well plate for subsequent experiments. The relationship between $\log _{2}$ of initial inoculum and $\mathrm{OD}_{405}$ was consistent with the agonist-response curve as well, which further indicated that the RAW264.7-pNF-kB-SEAP cells were successfully established, stable, and can be applied to the screening of NF-kB-dependent anti-inflammatory compounds.

To activate NF- $\mathrm{kB}$ in this cell model, we treated the RAW264.7-pNF-kB-SEAP cells with 3 NF-kB pathway agonists: LPS, TNF- $\alpha$, and polyI:C for $24 \mathrm{~h}$. The results showed that there was no difference after TNF- $\alpha$ treatment (Additional file 1: Figure S1A and Additional file 2), while SEAP secretion was significantly up-regulated after treatment with 10nM polyI:C (Additional file 1: Figure S1B and Additional file 2) and 10 and $100 \mathrm{ng} / \mathrm{mL}$ LPS (Fig. 2c and Additional file 2), compared with the control (DMSO group). We found that the relation between excitation ratio of SEAP expression and the concentration of 
Table 1 The inhibition ratio of the 130 chemicals

\begin{tabular}{|c|c|c|c|c|c|}
\hline Compound No. & Inhibition ratio (\%) & Compound No. & Inhibition ratio (\%) & Compound No. & Inhibition ratio (\%) \\
\hline w1 & $-11.65 \pm 1.29$ & $k 26$ & $-14.74 \pm 2.00$ & $\mathrm{z4}$ & $-44.29 \pm 19.53$ \\
\hline w2 & $-23.07 \pm 8.68$ & $k 27$ & $-16.02 \pm 1.17$ & $z 5$ & $-39.52 \pm 17.50$ \\
\hline w3 & $-9.38 \pm 1.53$ & $k 28$ & $1.64 \pm 3.12$ & $z 6$ & $-19.94 \pm 3.85$ \\
\hline w4 & $-2.92 \pm 2.03$ & k30 & $-14.45 \pm 3.33$ & z7 & $-35.50 \pm 16.85$ \\
\hline w5 & $-12.74 \pm 2.48$ & k32 & $-13.99 \pm 2.33$ & z8 & $-29.85 \pm 15.10$ \\
\hline w6 & $-6.40 \pm 2.60$ & k34 & $6.06 \pm 2.06$ & z9 & $-35.72 \pm 16.32$ \\
\hline w7 & $2.21 \pm 3.22$ & k35 & $-9.43 \pm 2.00$ & $z 10$ & $-13.67 \pm 11.87$ \\
\hline w8 & $4.85 \pm 5.55$ & k36 & $4.81 \pm 8.98$ & $z 11$ & $-21.48 \pm 7.93$ \\
\hline w9 & $6.41 \pm 7.79$ & k37 & $-4.56 \pm 0.75$ & $z 12$ & $-22.78 \pm 7.29$ \\
\hline W10 & $27.20 \pm 5.91^{* * *}$ & k38 & $-6.22 \pm 1.40$ & $z 13$ & $-38.60 \pm 16.45$ \\
\hline w11 & $12.99 \pm 0.34^{* *}$ & k33 & $-4.24 \pm 3.08$ & z14 & $-42.24 \pm 19.10$ \\
\hline w12 & $4.49 \pm 8.32$ & $k 40$ & $-4.84 \pm 0.62$ & z15 & $-9.32 \pm 10.93$ \\
\hline w13 & $-2.24 \pm 2.98$ & $\mathrm{x} 1$ & $-10.09 \pm 0.37$ & $z 16$ & $-17.9 \pm 13.51$ \\
\hline w14 & $-2.85 \pm 2.72$ & $\times 2$ & $-13.39 \pm 0.83$ & $z 17$ & $-16.95 \pm 15.87$ \\
\hline w15 & $42.95 \pm 28.87^{*}$ & $\times 3$ & $-6.83 \pm 2.87$ & $\mathrm{z} 18$ & $-10.58 \pm 10.06$ \\
\hline w19 & $15.76 \pm 5.56^{* *}$ & $x 4$ & $-9.21 \pm 3.05$ & z19 & $6.12 \pm 6.76$ \\
\hline$w 20$ & $29.82 \pm 10.13^{* *}$ & $\times 5$ & $-2.57 \pm 1.20$ & $z 20$ & $-13.51 \pm 4.73$ \\
\hline w21 & $-10.04 \pm 1.59$ & $x 6$ & $-8.41 \pm 0.48$ & z21 & $-4.97 \pm 4.55$ \\
\hline w22 & $-12.64 \pm 4.55$ & $x 8$ & $-3.20 \pm 0.43$ & z22 & $-2.92 \pm 4.35$ \\
\hline w23 & $-12.17 \pm 3.76$ & $\times 9$ & $9.43 \pm 1.85^{*}$ & s1 & $15.23 \pm 1.85^{* *}$ \\
\hline$k 1$ & $-8.45 \pm 3.57$ & $\times 10$ & $-4.75 \pm 0.60$ & s2 & $6.82 \pm 1.28$ \\
\hline k2 & $-2.86 \pm 1.86$ & $x 11$ & $-3.74 \pm 0.85$ & s3 & $26.57 \pm 6.43^{* * *}$ \\
\hline k3 & $-5.10 \pm 1.92$ & $\times 12$ & $-3.49 \pm 0.63$ & s4 & $10.68 \pm 3.97^{*}$ \\
\hline k4 & $-11.37 \pm 3.07$ & $\times 13$ & $-6.20 \pm 9.91$ & $s 5$ & $-0.58 \pm 3.33$ \\
\hline k5 & $-4.99 \pm 1.116$ & $\times 14$ & $-14.30 \pm 9.40$ & s6 & $-3.90 \pm 6.65$ \\
\hline k6 & $-2.10 \pm 1.52$ & $\times 15$ & $-20.12 \pm 16.57$ & s7 & $-11.21 \pm 2.75$ \\
\hline k7 & $-4.36 \pm 2.82$ & $\times 16$ & $-37.86 \pm 6.55$ & s8 & $-14.82 \pm 6.92$ \\
\hline k8 & $-2.22 \pm 3.39$ & $\times 17$ & $-31.71 \pm 2.97$ & s9 & $-9.54 \pm 3.42$ \\
\hline k9 & $-6.56 \pm 2.32$ & $\times 18$ & $-41.94 \pm 8.21$ & s10 & $-23.73 \pm 7.42$ \\
\hline k10 & $-4.30 \pm 2.47$ & $\times 19$ & $-26.51 \pm 20.62$ & s11 & $-14.65 \pm 5.85$ \\
\hline k11 & $-3.05 \pm 2.17$ & $\times 20$ & $-14.09 \pm 8.09$ & $\mathrm{~s} 12$ & $-6.06 \pm 25.05$ \\
\hline k12 & $5.12 \pm 0.42$ & $x 21$ & $-25.66 \pm 11.07$ & s13 & $-11.09 \pm 2.86$ \\
\hline k13 & $8.26 \pm 2.57$ & $\times 22$ & $5.25 \pm 18.74$ & s14 & $-4.31 \pm 2.64$ \\
\hline k14 & $9.31 \pm 2.81$ & $x 23$ & $4.80 \pm 1.82$ & s15 & $20.42 \pm 2.62^{* * *}$ \\
\hline k15 & $5.30 \pm 1.41$ & $\times 24$ & $7.56 \pm 9.16$ & s16 & $4.57 \pm 5.97$ \\
\hline$k 16$ & $12.63 \pm 2.95^{*}$ & $\times 25$ & $-7.50 \pm 5.60$ & s17 & $11.34 \pm 1.90$ \\
\hline $\mathrm{k} 17$ & $6.19 \pm 0.75$ & $\times 26$ & $3.62 \pm 5.16$ & $s 18$ & $16.33 \pm 9.43^{*}$ \\
\hline k18 & $-6.14 \pm 0.96$ & $\times 27$ & $0.19 \pm 3.65$ & $s 19$ & $-5.27 \pm 3.55$ \\
\hline$k 20$ & $3.80 \pm 0.79$ & $x 28$ & $11.67 \pm 10.08$ & $s 20$ & $19.63 \pm 2.34^{* * *}$ \\
\hline k21 & $-2.91 \pm 0.58$ & $\times 29$ & $-1.12 \pm 8.86$ & $s 22$ & $6.79 \pm 4.18$ \\
\hline
\end{tabular}


Table 1 The inhibition ratio of the 130 chemicals (Continued)

\begin{tabular}{llllll}
\hline$k 22$ & $-0.02 \pm 2.30$ & $x 30$ & $-3.87 \pm 3.32$ & $s 23$ & $-6.96 \pm 4.91$ \\
$k 23$ & $1.35 \pm 1.78$ & $z 1$ & $-23.43 \pm 13.80$ & $s 24$ & $-16.02 \pm 6.30$ \\
$k 24$ & $-2.47 \pm 2.41$ & $z 2$ & $-28.88 \pm 17.48$ & PDTC & $50.35 \pm 1.36$ \\
$k 25$ & $-4.87 \pm 1.48$ & $z 3$ & $-19.87 \pm 11.88$ & & \\
\hline
\end{tabular}

The result showed as the format of "Mean \pm SEM"

The "*" means that the column had significant difference compared with the control, $P<0.05 ;{ }^{* *} P<0.01 ;$ and ${ }^{* * *} P<0.001$

LPS was according to the excitation-response curve, $\mathrm{R}^{2}=$ 0.9643 , and this result indicated that the effect of LPS on SEAP secretion of RAW264.7-pNF-kB-SEAP cells was dose-dependent (Fig. 2c and Additional file 2). However, as traditional agonists to Toll-like receptor -3 and TNFR, activation of polyI:C and TNF- $\alpha$ to NF- $\mathrm{KB}$ should be present in this reporter gene system; therefore, we tested for the effects of LPS, polyI:C, and TNF- $\alpha$ on SEAP at different time points. The results showed that SEAP secretion was up-regulated only after treatment with $10 \mathrm{nM}$ polyl:C and $10 \mathrm{ng} / \mathrm{mL}$ TNF- $\alpha$ for $12 \mathrm{~h}$, while there was significant up-regulation at 3 time points after treatment with $100 \mathrm{ng} / \mathrm{mL}$ LPS, compared with their corresponding controls (DMSO group) (Additional file 1: Figure S1C) and Additional file 2. Therefore, the optimal agonist of NF- $\mathrm{kB}$ was LPS, at $100 \mathrm{ng} / \mathrm{mL}$ with treatment duration of $24 \mathrm{~h}$, respectively (Fig. 2c and Additional file 2).

In order to select a NF- $\kappa B$ inhibitor as positive control in the drug screening system for anti-inflammatory compounds, the RAW264.7-pNF-кB-SEAP cells were pretreated with NF- $\mathrm{KB}$ inhibitors, PDTC and BAY117085 for $6 \mathrm{~h}$ before treatment with $100 \mathrm{ng} / \mathrm{mL}$ LPS for $24 \mathrm{~h}$. The results showed that PDTC significantly downregulated SEAP secretion by these cells compared to the control group, at concentrations ranging from 10 to $100 \mu \mathrm{M}$ (Fig. 2d and Additional file 2), while BAY117085 significantly decreased SEAP secretion by these cells compared to the control group at concentrations ranging from 0.1 to $50 \mu \mathrm{M}$ (Fig. 2e and Additional file 2). Although the inhibitory effect of BAY117085 seemed to be superior to that of PDTC, some dead cells were observed with BAY117085 at concentration of $100 \mu \mathrm{M}$. Therefore, PDTC was selected as the positive control in the drug screening system for anti-inflammatory compounds. In addition, as the inhibition ratio of $10 \mu \mathrm{M}$ PDTC was nearer to $50 \%$, the concentration of $10 \mu \mathrm{M}$ PDTC was used in subsequent screening.

Thus, the drug screening system on the basis of the RAW264.7-pNF-kB-SEAP was established. The procedure of screening was as follows: the RAW264.7-pNF- $\mathrm{kB}-$ SEAP cells were inoculated in the 96-well plate at a concentration of 40,000cells/well and incubated with high-glucose DMEM without phenol red at $37{ }^{\circ} \mathrm{C}$ for $2 \mathrm{~h}$ to allow adherence. These cells were then treated with $100 \mathrm{ng} / \mathrm{mL}$ LPS for $24 \mathrm{~h}$ after pre-treatment with $10 \mu \mathrm{M}$ test compounds, $1 \%$ DMSO (blank control), and $10 \mu \mathrm{M}$ PDTC (positive control) for $6 \mathrm{~h}$. The activity of SEAP in the culture supernatant was determined. Lastly, the inhibitory ratio of compounds was calculated as compared to blank control.

\section{Screening of 130 compounds as NF-KB inhibitors using} the drug screening system and verification of the inhibitory effect of the screened compound W10

Using our new drug screen system, we screened 130 compounds. The results showed that 13 compounds had remarkable inhibitory effect on the secretion of SEAP (Table 1 and Additional file 2). Of these, 8 compounds $(P<0.01)$ (Table 1 and Additional file 2) were analysed once again. The results showed that there was no difference in their inhibition ratio between the primary and the repeat screens (Table 2 and Additional file 2). The inhibition ratio of the compound W10 was stable in the 2 screenings (Table 2 and Additional file 2). In contrast, the inhibition ratio of the compound S15 was significantly increased in the repeat than in the primary screen (Table 2 and Additional file 2). We chose compound W10 to carry out subsequent studies.

The compound structure of W10 is shown in Fig. 3. We planned for further studies on W10 at the molecular mechanism of the compound stable inhibition on the NF-kB. RAW264.7 cells were treated with W10 for $2 \mathrm{~h}$ and then with LPS for 6,12 , and $24 \mathrm{~h}$. Transcription of

Table 2 Comparison of inhibition ratio of 8 chemicals between the primary screening and the secondary screening

\begin{tabular}{lcc}
\hline $\begin{array}{c}\text { Compound } \\
\text { No }\end{array}$ & $\begin{array}{l}\text { Inhibition ratio(\%) from } \\
1^{\text {st }} \text { creening }\end{array}$ & $\begin{array}{l}\text { Inhibition ratio(\%) from } 2^{\text {nd }} \\
\text { screening }\end{array}$ \\
\hline w10 & $27.20 \pm 5.91$ & $26.64 \pm 1.41$ \\
W11 & $12.99 \pm 0.34$ & $23.96 \pm 6.22$ \\
w19 & $15.76 \pm 5.57$ & $12.44 \pm 1.08$ \\
W20 & $29.82 \pm 10.13$ & $7.73 \pm 1.18$ \\
s1 & $15.23 \pm 1.85$ & $10.12 \pm 1.24$ \\
s3 & $26.57 \pm 6.43$ & $20.35 \pm 0.86$ \\
S15 & $20.42 \pm 2.62$ & $41.90 \pm 0.55$ \\
s20 & $19.63 \pm 2.34$ & $22.52 \pm 0.81$ \\
PDTC & $40.97 \pm 1.32$ & $52.07 \pm 3.45$
\end{tabular}

The results showed as the format of"Mean \pm SEM" 


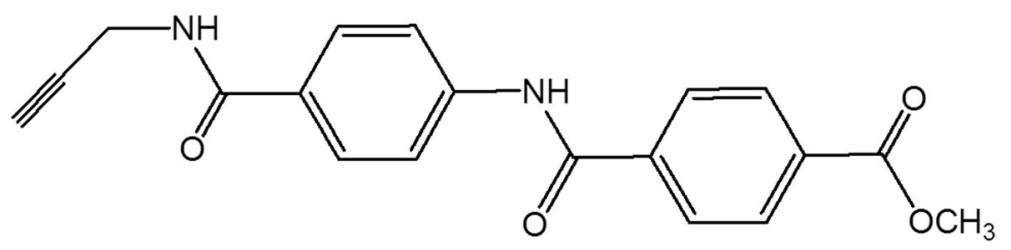

Fig. 3 The structure of w10. Methyl 4-((4-(prop-2-ynylcarbamoyl) phenylcarbamoyl) benzoate (w10)

COX-2 and IL6 was activated by NF-kB. The result showed that the transcription of COX-2 and IL6 was upregulated by LPS, but W10 did not inhibit their upregulation induced by LPS (Additional file 1: Figure S2 and Additional file 2). The transcription of COX-2, ICAM1 and MCP1 was significantly inhibited in HepG 2 cells after treatment with W10 for $24 \mathrm{~h}$, whereas, transcription inhibition by MCP1 remained for only $48 \mathrm{~h}$ (Fig. 4a, b, and c and Additional file 2). The transcription of COX-2 and ICAM1 was significantly inhibited in HeLa cells after treatment with W10 for $24 \mathrm{~h}$ and this inhibition remained for $48 \mathrm{~h}$. Additionally, the transcription of MCP1 was significantly inhibited in HeLa cells after treatment with W10 for $48 \mathrm{~h}$ (Fig. 4d, e, and f and Additional file 2). As the transcription of ICAM1 and MCP1 were inhibited with W10, we detected whether W10 inhibited the migration of tumour cells with scratch testing. The results showed that the scratches in HeLa cells were significant narrow down in control group for $24 \mathrm{~h}$ and $48 \mathrm{~h}$. However, the scratches in HeLa cells have not vary significantly for $24 \mathrm{~h}$ and $48 \mathrm{~h}$ in W10 treated group (Fig. 4g and h and Additional file 2).

\section{Discussion}

The most important parameter for a drug screening system is stability. To this end, we constructed a stable recombinant cell line, selected a reporter gene with a prolonged half-life, used standard detection methods for the reporter gene, and selected an optimal agonist and inhibitor for this system. Although a drug screening system based on instantaneous transfection of reporter gene has been previously reported, we constructed a stable reporter gene recombinant cell line, since transfection of the RAW264.7 cell line selected for this system is a challenge. We constructed a stable reporter gene recombinant cell line to provide a foundation for stability of the screening system. Similarly, while selecting the reporter gene, we chose SEAP rather than luciferase, which is otherwise popular in drug screening methods. Due to its sensitivity and ease of detection, luciferase is suited to testing cells in which a transcription promoter is momentarily activated or inhibited [26]. However, signal pathway activation and cascade mechanisms vary. For example, persistent effect as seen with LPS activating NF-kB through binding with TLR4, pulsating effect as seen with TNF- $\alpha$ activating NF- $\kappa B$ through binding with TNFR [27], feedback effect as seen with HDL inhibiting proinflammatory gene transcription by activating ATF3 [28]. These effects occur in different periods and are difficult to detect in a single test based on luciferase. Other than the instant effect, we focused on the complete effect of the compound on cells within a period, therefore we chose the reporter gene SEAP which has a longer half-life and lower distinguishing ability, to construct the drug screen system [29]. For SEAP testing, we established a standard curve of alkaline phosphatase activity that improves the stability of the drug screening system. The standard curve of alkaline phosphatase activity translates the screening results into absolute, quantified values and provides uniformity to the screening results from different time points. In the screening process, we chose an optimal agonist and inhibitor of NF- $\mathrm{kB}$ to treat the reporter gene recombinant cell line. LPS was found to significantly induce NF- $\mathrm{KB}$ activation for a long period $(24 \mathrm{~h})$. The significant up-regulation of SEAP expression was sustained throughout this period. This persistent and significant activation of NF- $\mathrm{kB}$ authenticates the inhibitory effect of the candidate compounds and diminishes false-negative error. PDTC is recognized as a typical NF- $\mathrm{KB}$ inhibitor. This was chosen as the optimal inhibitor of NF- $\mathrm{kB}$ in our drug screening system. During screening, we treated cells with PDTC at the same concentration as candidate compounds, which was near to the $\mathrm{IC}_{50}$ of PDTC for NF-kB. While the samples treated with PDTC were taken as positive control, we could gauge whether inhibition of SEAP expression by PDTC skewing the results indicated if the cells are unusually sensitive due to age, mutation or other reasons. PDTC as positive control compound helped ensure that the drug screening system was stable. Besides, we tested the inhibition of NF- $\mathrm{kB}$ by the compound W10 with RT-qPCR, which showed that W10 inhibited transcription of genes regulated by NF- $\mathrm{KB}$ and the inhibition of W10 remained for $48 \mathrm{~h}$. Testing and verification of transcription of genes promoted by NF- $\mathrm{kB}$ is working for maintaining stability of the drug screening system. After screening 130 compounds using the system, we 

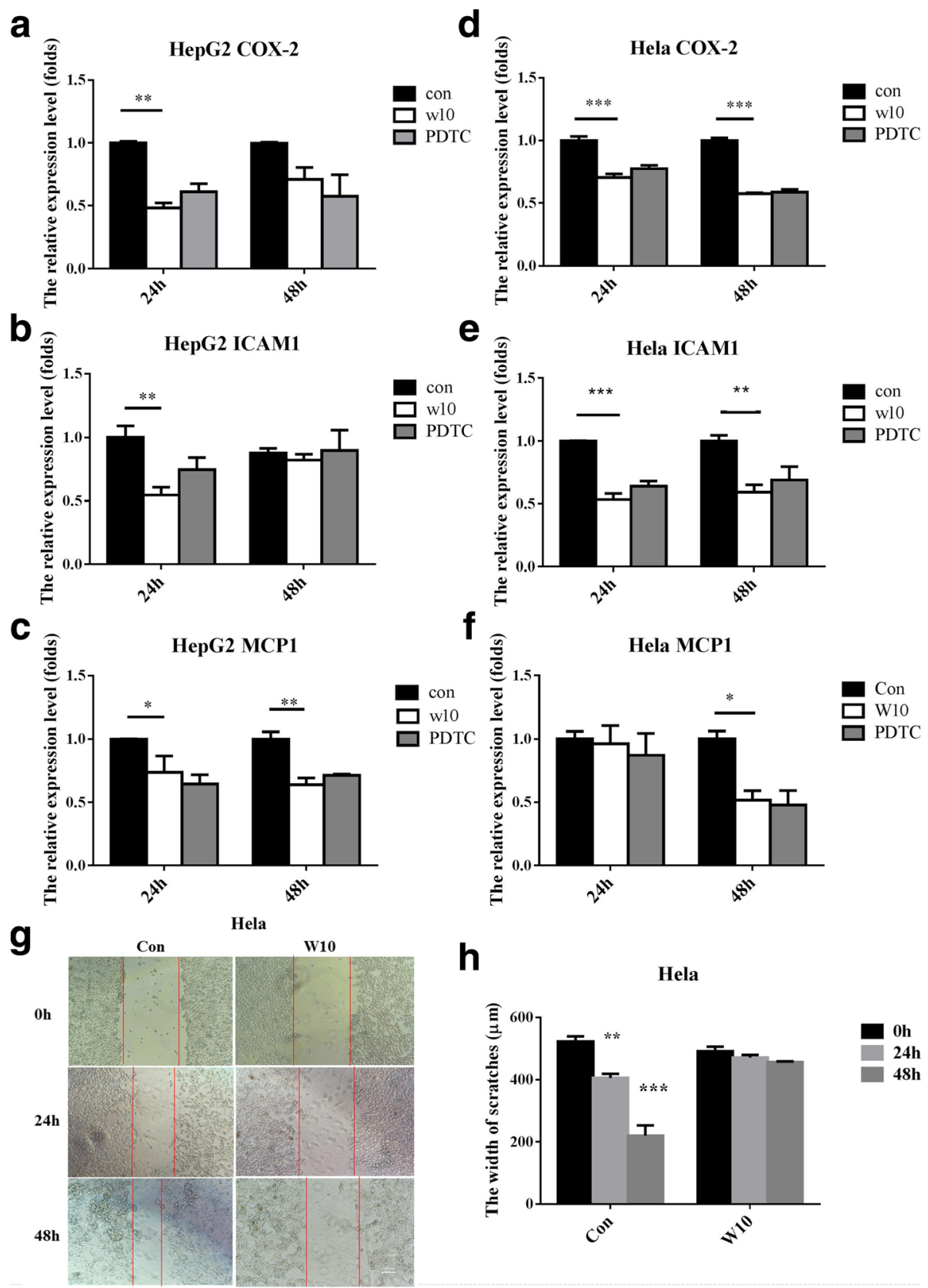

h Hela

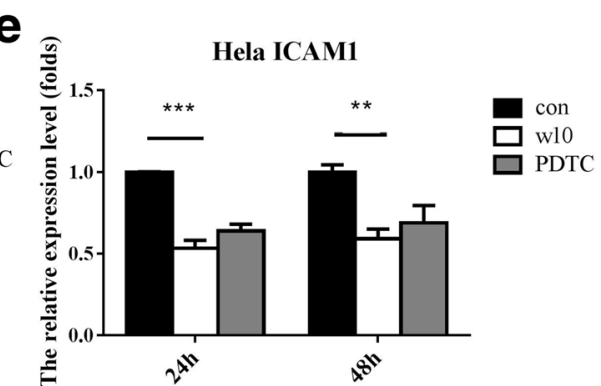

Fig. 4 The effectsto HepG2 and HeLa cellstreated with W10 in relative gene and scratches. The relative expression level of COX-2 (a), ICAM1 (b) and MCP1 (c) in HepG 2 cells after treatment with control, PDTC, or W10 for 24 or 48 h. The relative expression level of COX-2 (d), ICAM1 (e), and MCP1 (f) in HeLa cells after treatment with control, PDTC, or W10 for 24 or $48 \mathrm{~h}$. The width of scratchesin Hela cells after treatment with control and W10 for $24 \mathrm{~h}$ or $48 \mathrm{~h}$ expressed in photograph $(\mathbf{g})$ and histogram $(\mathbf{h})$. The data are expressed as mean \pm SEM from 3 independent experiments. The ${ }^{\mu *} "$ indicates that the column had significant difference compared with the control in group

evaluated stability of the system in terms of ease to operate and perform the test, while maintaining control.

From our study, we found that W10 did not inhibit the transcription of genes downstream of NF- $\mathrm{kB}$ activated by LPS; rather, W10 inhibited the transcription of genes downstream of the NF-KB signal in tumour cell lines that
NF- $\mathrm{kB}$ persistently activated, and part of the inhibitory effect persisted until $48 \mathrm{~h}$. These results indicated that W10 is specific to NF- $\mathrm{kB}$. LPS induces gene transcription not only via NF-kB; W10 specifically inhibited the upregulation of genes from NF-kB. Therefore, W10 did not inhibit the up-regulation of genes induced by the LPS signal on the whole. This phenomenon shows that the drug 
screening system we constructed is highly specific to its target and therefore, W10 can be allied to cancer research and therapy.

\section{Conclusion}

We constructed a drug screening system targeting the transcription factor NF- $\kappa \mathrm{B}$, based on the cell line RAW264.7. In this drug screening system, unstable factors were eliminated by standardizing each index and choosing the optimal control, which increased the stability and accuracy of the drug screening system, allowing for a simple and fast assay. The compound W10 were selected with the drug screening system we constructed. In our further studies, W10 was detected to inhibit the transcription of COX-2, ICAM1 and MCP1 in Hela and HepG2 and inhibit the migration of Hela cells.

\section{Additional files}

Additional file 1: Table S1, Figure S1 and Figure S2

Additional file 2: Supporting data for Fig. 2, Fig. 4, Table 1, Table 2, Additional file 1: Figure S1 and Figure S2. (XLSX 66 kb)

\section{Abbreviations}

BAY11-7085: (2E)-3-[[4-(1,1-Dimethylethyl)phenyl]sulfonyl]-2-propenenitrile; CIAP: Calf intestine alkaline phosphatase; COX-2: Cyclooxygenase-2; DEA: Diethanolamine; ICAM1: Intercellular adhesion molecule; IL1及: Interleukin-1 $\beta$; LPS: Lipopolysaccharide; MCP1: Monocyte chemoattractant protein 1; NF-kB: Nuclear factor-kB; PDTC: Pyrrolidinedithiocarbamate; PNPP: P-nitrophenyl phosphate; SEAP: SEAP; TNF-a: Tumour necrosis factor TNF- $\mathrm{C}$

\section{Acknowledgements}

The authors need to thank Liesu Meng (School of Basic Medical Sciences, Xi'an Jiaotong University Health Science Centre) and Wenhua Zhu (School of Basic Medical Sciences, Xi'an Jiaotong University Health Science Centre) for supplying methods of RAW264.7 stable cell line construction. We also thank Teng Shao and Borui Kang for supplying chemicals in drug screening. In addition, we are very grateful to Mr. Ezra Kombo Osoro for critical reading and linguistic correction of the manuscript.

\section{Funding}

The subject was supported by: the National Natural Science Foundation of China (No. 81370952), the Key Science and Technology Project of Shaanxi Province (No. 2013 K21-22-03) and the Fundamental Research Funds for the Central Universities (No. xjj20100031). Reporter gene vector recombination and standard curve construction of alkaline phosphatase activity were supported by the National Natural Science Foundation of China (No. 81370952). Optimizing the drug screening system with RAW264.7-pNF-kBSEAP, synthesis and identification of W10 were supported by the Fundamental Research Funds for the Central Universities (No. xjj20100031). Agriculture and treatment of Hela and HepG2 cells, RNA isolation and realtime-qPCR assy were supported bythe Key Science and Technology Project of Shaanxi Province (No. 2013 K21-22-03).

\section{Availability of data and material}

The supporting data of our figures and tables is presented in Additional file 1 \& Additional file 2 . The information of the chemicals in this manuscript could be requested from co-author Sanqi Zhang.

\section{Authors' contributions}

$Y L$ conducted the whole experiment and manuscript writing. $Y L, J R, X L$ constructed the reporter gene vector. $Y L$ and $X L$ made the standard curve of alkaline phosphatase activity. YL, JL and JY optimized the drug screening system with RAW264.7-pNF-kB-SEAP. XW synthesized and identified W10 compounds. $Y L$ and $L L$ conducted the cell experiments. $Y L$ and $H Y$ performed the RNA isolation and realtime-qPCR. SZ guided the pharmacy part of the manuscript. SL and DL was responsible for funds raising, experiment designing and paper appraisal. All authors above read and approved the final version of this manuscript.

\section{Competing interests}

The authors declare that they have no competing interests.

\section{Consent for publication}

Not applicable.

\section{Ethics approval and consent to participate}

Not applicable.

\section{Author details}

'Department of Biochemistry and Molecular Biology, School of Basic Medical Sciences, Xi'an Jiaotong University Health Science Centre, Xi'an, Shaanxi 710061, People's Republic of China. ${ }^{2}$ Key Laboratory of Environment and Genes Related to Diseases (Xi'an Jiaotong University), Ministry of Education of China, Xi'an, Shaanxi 710061, People's Republic of China. ${ }^{3}$ Department of Medicinal Chemistry, School of Pharmacy, Xi'an Jiaotong University Health Science Centre, Xi'an, Shaanxi 710061, People's Republic of China.

${ }^{4}$ Department of Reproductive Medicine, The Fourth Hospital of Xi'an, Xi'an, Shaanxi, People's Republic of China.

Received: 10 August 2016 Accepted: 19 December 2016

Published online: 18 January 2017

\section{References}

1. Olefsky JM, Glass CK. Macrophages, inflammation, and insulin resistance. Annu Rev Physiol. 2010;72:219-46.

2. Therese Böhm HB, Marzieh N, et al. Food-derived peroxidized fatty acids may trigger hepatic inflammation: A novel hypothesis to explain steatohepatitis. J Hepatol. 2013;59:8.

3. Ben-Neriah Y, Karin M. Inflammation meets cancer, with NF-kappaB as the matchmaker. Nat Immunol. 2011;12(8):715-23.

4. Pearce EL, Pearce EJ. Metabolic pathways in immune cell activation and quiescence. Immunity. 2013;38(4):633-43.

5. Esser NLH, De Roover $L$, et al. Obesity phenotype is related to NLRP3 inflammasome activity and immunological profile of visceral adipose tissue. Diabetologia. 2013;56(11):2487-97.

6. Noy R, Pollard JW. Tumor-associated macrophages: from mechanisms to therapy. Immunity. 2014:41(1):49-61.

7. Hayden MS, Ghost S. Shared principles in NF-kappaB signaling. Cell. 2008; 132(3):344-62.

8. Wullaert A. Role of NF-kappaB activation in intestinal immune homeostasis. Int J Med Microbiol. 2010;300(1):49-56.

9. Basak S, Hoffmann A. Crosstalk via the NF-kappaB signaling system. Cytokine Growth Factor Rev. 2008;19(3-4):187-97.

10. Gilmore T. The Rel/NF-kappaB Signal Transduction Pathway. http://www.bu. edu/nf-kb/gene-resources/target-genes/. Accessed 27 Dec 2016.

11. McColl BWA, Rothwell SM, et al. Systemic infection, inflammation and acute ischemic stroke. Neuroscience. 2009;158(3):1049-61.

12. Anand $P$, Sung $B$, Kunnumakkara $A B$, et al. Suppression of pro-inflammatory and proliferative pathways by diferuloylmethane (curcumin) and its analogues dibenzoylmethane, dibenzoylpropane, and dibenzylideneacetone: role of Michael acceptors and Michael donors. Biochem Pharmacol. 2011;82(12):1901-9.

13. Libby P. Inflammation and Atherosclerosis. Circulation. 2002;105(9):1135-43.

14. Oeckinghaus $\mathrm{AH}$, Ghosh MS, et al. Crosstalk in NF-kappaB signaling pathways. Nat Immunol. 2011;12(8):695-708.

15. Yadav VR, Prasad S, Gupta SC, et al. 3-Formylchromone interacts with cysteine 38 in p65 protein and with cysteine 179 in IkappaBalpha kinase, leading to down-regulation of nuclear factor-kappaB (NF-kappaB)-regulated gene products and sensitization of tumor cells. J Biol Chem. 2012;287(1):245-56.

16. Macarron RB, Bojanic MN, et al. Impact of high-throughput screening in biomedical research. Nat Rev Drug Discov. 2011;10(3):188-95.

17. Zanella F, Lorens JB, Link W. High content screening: seeing is believing. Trends Biotechnol. 2010;28((5):237-45. 
18. Darnay BG, Ni J, More PA, et al. Activation of NF- B by RANK Requires Tumor Necrosis Factor Receptor-associated Factor (TRAF) 6 and NF- Binducing Kinase. J Biol Chem. 1999;274:8.

19. O'Neill LAJ, Paul B. 2-Mercaptoethanol restores the ability of nuclear factor $\mathrm{KB}(\mathrm{NF} K \mathrm{~KB})$ to bind DNA in nuclear extracts from interleukin 1-treated cells incubated with pyrollidine dithiocarbamate (PDTC). Biochem J. 1996;320:7.

20. Hongyu $\mathrm{N}$, Ergin $\mathrm{M}$, Qin $\mathrm{H}$, et al. Analysis of expression of nuclear factor $\mathrm{KB}$ (NF-KB) in multiple myeloma: downregulation of NF-KB induces apoptosis. Br J Haematol. 2001;115:8.

21. Jianga CS, Wang XM, SQi Z, et al. Discovery of 4-Benzoylamino-N-(Prop-2yn-1-yl)benzamides as Novel MicroRNA-21 Inhibitors. Bioorg Med Chem. 2015;23(19):6510-9. Available online.

22. Kang BR, Wang J, Li H, et al. Synthesis and antitumor activity evaluation of 2-arylisoquinoline-1,3(2H,4H)-diones in vitro and in vivo. Med Chem Res. 2014;23(3):1340-49.

23. Zuo MZ, Lu YW, et al. Synthesis and biological evaluation of $\mathrm{N}$-aryl salicylamides with a hydroxamic acid moiety at 5-position as novel HDACEGFR dual inhibitors. Bioorg Med Chem. 2012;20(14):4405-12.

24. Xuan W, Ding W, Hong-xiang H, San-qi Z. Synthesis and cytotoxic activity of diaryl urea derivatives with a 4-methylpiperazinylcarbonyl moiety. Med Chem Res. 2012;22(8):3857-62.

25. Shao T, Wang J, Chen JG, et al. Discovery of 2-methoxy-3-phenylsulfonamino5-(quinazolin-6-yl or quinolin-6-yl)benzamides as novel PI3K inhibitors and anticancer agents by bioisostere. Eur J Med Chem. 2014;75:96-105.

26. Dube A, Gupta R, Singh N. Reporter genes facilitating discovery of drugs targeting protozoan parasites. Trends Parasitol. 2009;25(9):432-9.

27. Lahav G, Purvis JE. Encoding and decoding cellular information through signaling dynamics. Cell. 2013;152:12.

28. De Nardo DL, Kono LI, et al. High-density lipoprotein mediates antiinflammatory reprogramming of macrophages via the transcriptional regulator ATF3. Nat Immunol. 2014;15(2):152-60.

29. Sen $M$, Ino K, Shiku $H$, et al. A new electrochemical assay method for gene expression using HeLa cells with a secreted alkaline phosphatase (SEAP) reporter system. Biotechnol Bioeng. 2012;109:5.

\section{Submit your next manuscript to BioMed Central and we will help you at every step:}

- We accept pre-submission inquiries

- Our selector tool helps you to find the most relevant journal

- We provide round the clock customer support

- Convenient online submission

- Thorough peer review

- Inclusion in PubMed and all major indexing services

- Maximum visibility for your research

Submit your manuscript at www.biomedcentral.com/submit

) Biomed Central 